\title{
Ubuntu: Alterity as a Perspective for Peace
}

\author{
Flora Strozenberga, Willis Santiago Guerra Filhoa, Luiz Otávio Ferreira Barreto Leitea, Edna Raquel \\ Santos Hogemanna, Milanna Nagiba, Hellen Cristina Silva de Oliveiraa, Matheus Novais da Silva ${ }^{a}$, Ana \\ Carolina Antão
}

\begin{abstract}
This paper looks for deepening the connections among peace, intercultural dialogue, and communalism in the light of Ubuntu, an ethical concept that emphasizes the alliances constructed between people and the relations established by them, and is seen as fundamental to the African thought of the groups that adopt Bantu languages. It develops an original exercise in diatopical hermeneutics - a methodology proposed by Raimon Panikkar, taking as the main goal to approach the Western ethical and political thought to the epistemic and ontological category of Ubuntu, recognized in the Zulu maxim umuntu ngumuntu ngabantu (a person is a person through other persons). It chooses as the basis of such study some contemporary thinkers as Lévinas, Bauman, Ramose, Chuwa, Kunene, and Nussbaum, who show a common concern with reverting a context of war and disregard of the integrity of human beings, connected to an ethics of alterity, zealous of the values of conviviality and respect for the cultural differences. It reveals the political dimension of Ubuntu and the impacts of this conception on the process of facing the problems of human rights in post Apartheid South Africa. Grounded on such transdisciplinary reflexion, it tries to point through a path to the implementation of policies for peace based on interculturality and communalism within different cultures.
\end{abstract}

\section{Keywords}

Ubuntu, peace, ethical and political thought, respect for the other, communalism

The broader exercise of the right to peace-included by Bobbio (2004) among the rights of a brand new generation, as the rights to genetic resources and memory - must be founded on a solid recognition of otherness.

This connection that is the main thread of reflection developed here will be unveiled for us through the African philosophical concept of ubuntu:

The concept ubuntu, like many African concepts, is not easily definable. To define an African notion in a foreign language and from an abstract as opposed to a concrete approach is to defy the very essence of the African world-view and can also be particularly elusive. (...) In one's own experience, ubuntu, it seems, is one of those things that you recognize when you see it. (...) In an attempt to define it, the concept has generally been described as a world-view of African societies and determining factor in the formation of perceptions which influence social conduct. (Mokgoro 1997: 2)

It is important to stress that the relationship among the clamor for peace, recognition of the other, and fostered dialogue between cultures, appears prominent in recent pronouncements. On the one hand,

aThe Federal University of State of Rio de Janeiro, Brazil

\section{Correspondent Author:}

Flora Strozenberg, Rua Marques de Abrantes, n. 119, apartamento 105, Flamengo, Rio de Janeiro, RJ, Brazil, Code Number 22230-060

E-mail: essenciais720@gmail.com 
the speech in the famous "House of Literature" in Oslo, by George Deek, an Arab Christian who serves as deputy Israeli ambassador to Norway, states:

If we wish to be successful in protecting our right to be different, if we want to have a future (in the Middle East), I think we need to agree-Jews, Muslims, and Christians: We will fight for the right of Christians to live their faith anywhere without fear, with the same passion with which we will fight for the right of Jews to live without fear.

On the other hand, the correspondence between the writers Etgar Keret, Israeli, and Sayed Kashua, a Palestinian exile in the USA, who writes in Hebrew and cultivates the habit of switching between the two cultures. They deplore without sacrificing the humor, the growing radicalization of the Middle East conflict and how this influences negatively on the coexistence of Jews and Arabs in Israel ${ }^{1}$.

But then what is the purpose of exploring the African concept of ubuntu, using Panikkar's hermeneutic thought (Panikkar 2002), designed as a fundamental way to promote the translation of knowledge, to make a connection between this conception and the Western ethical and political thought?

\section{ETHIC OF UBUNTU}

Ubuntu corresponds to an ancient African word meaning or suggesting that loyalty expands and makes consistent the relationship between people. The term comes from an ethical rule expressed in Zulu and Xhosa languages, and while we cannot date its origin, it is a mental state of being that prevails among the natives of Southern Africa until the present day-accordingly umuntu ngumtu ngabantu, which in Zulu means "a person is a person through other people" (Ramose 2003a).

In this maxim, it is possible to understand through the prism of communalism peculiar to African philosophy (possible to counter the individualism prevalent in Western thought) that each human being is only human, is only able to "individuate" by belonging to a human collective. The humanity of a person is determined by the alterity with others, through his humanity toward other human beings. In short, the existence of a person is through the existence of others in close relationship with itself. However, it is important to emphasize that the value of their humanity is entirely related to how she or he expresses humanity and the dignity of other human beings. The humanity of a person is thus defined by its ethical commitment with his next, no matter who he is man, woman, child, young, or old.

Relevance of the notion of ubuntu lies in our view, in the fact that this draws attention to the cultural disarmament and the strength of intercultural (and even inter-religious) dialogue, thought as being necessary conditions for the solution of the most serious problems faced by humankind and the urgent construction of a peaceful world.

The ethical and epistemological foundation of the contemporary reflections about the main issues concerning global bioethics can be found in the ubuntu world-view:

Human need for community, the kernel of Ubuntu ethics has been expressed by a number of Ubuntu scholars. John Mbiti, for example, states that Ubuntu ethics is based on the premise that an individual becomes conscious on this own existence, rights, duties, and obligations through other individuals, society, and the environment. There is no real personal existence independent of the society and its environment. Whatever affects one individual affects the entire society and its environment. Likewise, whatever affects the society affects each individual in it and that person's environment. Thus, "an individual can only say, I am because we are; and since we are, therefore, I am". (Chuwa 2014: 17)

The community spirit presents in African theory and practice is philosophically concentrated in categories such as ubuntu (where in its stem, namely ntu, it is possible to highlight the basic concept of life 
force) and communalism (Kimmerle 2006). People are conceived as a part of universal interplay of forces through the communities where they live, and they "are in close and permanent connection with the spiritual world of those who have passed away and these who are yet to be born" (Kimmerle 2006: 8).

Another Zulu maxim "It takes an entire village to raise a child" in Swanson's viewpoint (Swanson 2013), accurately reflects the spirit and intent of ubuntu. It is possible to infer from this statement that the community's strength derives from community support, and the dignity and identity are reached through mutual support, empathy, generosity, and the community's covenant. It comes appropriate to make a record: South Africa's apartheid period as such hateful regime threatened to erode the African way of life on ubuntu values, this by a remarkable irony, came to strengthen him to galvanize the collective support and creating solidarity among those who were members of the oppressed community.

\section{TOWARD A CULTURE OF TOLERANCE}

Adherence to the values identified in the two previously commented maxims, its knowledge may lead to the overcoming of fear that breeds prejudice and discrimination. Once attained such knowledge, seizes the spirit of tolerance, which is the value of human diversity and the quest to live with each other in a respectful, healthy way, going to the resolution of problems and disagreements by means of dialogue. A great part of this effort has been contemplated by the constitutions following that one set up at Bonn $(1948)^{2}$.

By the way, it is worth transcribing what are provisions of Article 1 of the Declaration of Principles on Tolerance UNESCO (United Nations Educational, Scientific, and Cultural Organization), dated 1995:

Article 1-Meaning of Tolerance

1.1 Tolerance is respect, acceptance, and appreciation of the rich diversity of our world's cultures, our forms of expression and ways of being human. It is fostered by knowledge, openness, communication, and freedom of thought, conscience, and belief. Tolerance is harmony in difference. It is not only a moral duty, it is also a political and legal requirement. Tolerance, the virtue that makes peace possible, contributes to the replacement of the culture of war by a culture of peace.

1.2 Tolerance is not concession, condescension, or indulgence. Tolerance is, above all, an active attitude prompted by recognition of the universal human rights and fundamental freedoms of others. In no circumstance can it be used to justify infringements of these fundamental values. Tolerance is to be exercised by individuals, groups, and states.

1.3 Tolerance is the responsibility that upholds human rights, pluralism (including cultural pluralism), democracy and the rule of law. It involves the rejection of dogmatism and absolutism and affirms the standards set out in international human rights instruments.

1.4 Consistent with respect for human rights, the practice of tolerance does not mean toleration of social injustice or the abandonment or weakening of one's convictions. It means that one is free to adhere to one's own convictions and accepts that others adhere to theirs. It means accepting the fact that human beings, naturally diverse in their appearance, situation, speech, behavior, and values, have the right to live in peace and to be as they are. It also means that one's views are not to be imposed on others.

The tolerance, which can be associated to expressions of ubuntu (Nussbaum 2003; Kunene 1996), becomes relevant (personal attitude not only) when one deliberates the resolution about human rights standards, such as the right to peace so esteemed by Bobbio (2004), which incidentally advocates the inseparability of such rights. The term should also be understood as toleration (Walzer 1999), which is different from tolerant attitude (tolerance), indicates a concrete institutional practice. Practice should be present within the communities attentive to ubuntu.

The right to identity that writers like Shutte (2001) and Ramose (2003a; 2003b) attempt to read in the ethics corresponding to ubuntu, interpreted as an African philosophy for peace, becomes effective when one accomplishes the strict implementation of policies for recognizing (as to those adopted by Mandela in 
South Africa), and not just when one focuses on equality. This right seems founded on the desire of communities and individuals to be different and to be treated differently.

It aims to individualize and distinguish, and not search equality. However, it is worth arguing that equality and non-discrimination-understood as basic principles of human rights, protected nowadays by different international treaties and conventions - presuppose the recognition of the other (inclusive of ethnic diversity) and the so-called right to difference.

Issues that have been faced by intellectuals of distinct scientific and academic education (Fraser 2007; Hall 2011; Donders 2005), often very attentive to the viewpoint of cultural relativism that cannot be underestimated in the approaches to the effects and social motivations of the cultural and political fragmentation growing in this age of globalization (Geertz 2011).

\section{ONTOLOGICAL AND POLITICAL DIMENSIONS OF UBUNTU}

Individual zealous for his right to cultural identity must see, as it is subsumed in the philosophy of ubuntu (Ramose 2003b) that is part of a more extensive and capable of displaying a permanent dynamism whole; they, in turn, do not appear as stable beings - are becoming, by joining other individuals. The religious South African Desmond Tutu, activist in human rights, who mobilized himself in a combative mode against apartheid in the $1980 \mathrm{~s}$, has made a valuable statement:

A person with ubuntu is open and available to others, after others, does not feel threatened when others are able and are good at something, because he/she is confident, because he/she knows that belongs to a greater whole, which decreases when others are humiliated or belittled, when others are tortured or oppressed.

Ramose (2003a; 2003b) makes evident that the ethics of ubuntu contemplates the possibility of constructing empowerment spaces of people thought as beings-in-common and an urgency of effecting, by force of collective individuation, pacts of coexistence between differences. These can be individual, ethnic, and religious. These are pacts that would not necessarily be universal, nor ideologically "multiculturalists". They would constitute the basis for building a more includent democracy that will cultivate the indispensable respect for otherness (Bauman 2001).

Without losing sight of diatopical hermeneutics proposed by Panikkar (2002), the authors argue that these spaces where people individuate themselves in a perennially becoming, considered in their belonging to a collective, would contain a near meaning of the Greek word ethos, meaning not just as it is identified in Plato or Aristotle, but as it appears in an original thinker like Heraclitus: ethos anthropous daimon, i.e., "the abode of man, the extraordinary". Two original thoughts get together here- the philosophy of ubuntu and that one corresponding to the vision of pre-Socratic world. Comprehensions become urgent to reassimilate.

Such task has been largely advanced by Lévinas, who sought (as if he had in mind the notion of ubuntu) to recover the force of ethics as the study of the condition of possibility to the human being open to the other, in a point where this can be fulfilled. In this proposal to envision a way to react to the exacerbated and often predatory individualism that shows itself prevalent nowadays.

The philosophy of ubuntu does not rely on any intention to hierarchize ontological, political, and ethical dimensions that such thought contains. This philosophy, as Ramose (2003b) stresses, gives an emphasis to transcendence, to the openness of the subject (the person) to alter.

At this point, it is possible to recognize a convergence of thinking with Lévinas's philosophical perspective (Lévinas 1993) to whom, however, ethics 
has absolute priority over ontology — positioning that marks its distance from Heideggerian vision.

From the perspective sustained by the philosopher of Humanism of other man, subjectivity cannot be conceived as a pure substance or moral monad. The human being - thing-for-itself (completely different therefore from the Kantian thing-in-itself) - reveals the capacity in immanence, thought as the only way to overcome the ego closed itself (solipsistic) and to deal with the alter, in short, to self, become responsible for the effective fulfillment of the moral law in front of the other:

Dis-inter-estedness of goodness: The other in your plea, which is an order, the other as face, the other that concerns me ("me regard" even when he/she doesn't look at me, others as close and always strange-goodness as transcendence; and I, who is obliged to respond, the irreplaceable, and so the chosen, thus truly unique). Goodness to the first one that comes, the man's right. Right of another man before all. (Lévinas 1997: 266)

Caring for others involves becoming sensitive to the face of another, to the vulnerability its appeal evidences and that $\mathrm{I}$, in fact, certify on me. Recognition of the other and through the other can serve as a basis for dialogue to peace.

The sui generis alliance between this understanding of Levinas and the defense of all axiology contained in the ethics of ubuntu can be the basis of an updated reflection on social justice. Bauman (2001) in his already classic community, opines based on Nancy Fraser, who put the issue of recognition in the context of social justice, rather than the context of "self-realization" (as sought Axel Honneth), may have a detoxification effect. This consists in removing the poison of sectarianism in the political sphere demands for recognition, avoiding entail physical or social separation, communication rupture, continuous demonstrations of hostility mutually exacerbated.

Such a position, it seems, was adopted with the support of ubuntu ethics, for the Commission of Truth and Reconciliation in South Africa chaired by Desmond Tutu when democratic transition occurred after the end of apartheid: The ubuntu is also the vivid expression of a alternative ecopolitics, antithesis of capitalist materialism, for stands against this ideological interpretation of reality through a native spiritual philosophy that is in greater harmony with the earth, its creatures and its life forms, and it tells about all mankind everywhere (Swanson 2013).

Cultivate ubuntu mean to Mandela and that religious leader-indeed, to all ubuntu leaders-to recover, with all the force, interaction with peers and non-peers. This allows bidirectionality and reciprocity among members of a large ethnically diverse community; in these ethnic differences lies the strength of this plural collective, a point of view invariably defended by Mandela (2013), and that has been reflected in many decisions of the South African Constitutional Court (Mokgoro 1997).

\section{CONCLUSIONS}

The development of social interaction skills should be, in the authors' view, spread at different educational, cultural, and industrial levels, preparing the ground for the implementation of peace policies. This will ensure a true education of skills in interpersonal relations, geared toward promoting and securing respect for others in their successes and failures, grid of friendships, social responsibility and self-control, the ability to negotiate, supportive values of helping and cooperation, as well as the repudiation of racism and discrimination. Also, it includes the conquest of a cognitive style - belonging as an alterity ethics in itself- to resolve interpersonal problems, resolving conflicts of interaction and the development of self-esteem.

The values contained in Ubuntu ethics - an ethic of care - cannot be neglected in the formulation and 
implementation of policies aimed at a world of peace. And they should also be taken into account when dealing with the most pressing problems of a global bioethics (Chuwa 2014).

\section{Notes}

1. The cheer of solidarism as principle constitutes one of the elective affinities which are possible to remark between both authors mentioned and that diplomat from Israel. One should sum up to this adoption of values that compose according to what will be proven, the basis of ubuntu ethics, stressing the respect for otherness and the esteem for ethical diversity. Values should be considered when facing the matters relative to global bioethics.

2. Modern constitutionalism, considered in itself as a political and legal movement, has been structured as an element that aims to guarantee the protection of fundamental rights - among them, the right to peace (Bonavides 2000) - the consequent rationalization and limitation of power. The unique way of understanding constitutionalism from a historical viewpoint, is to consider it as an instrument provided by civilization for the limitation of power; if power is absolute, as it happens in a number of non-secular states, constitutionalism ceases to make sense. In short: everything becomes political decision.

\section{References}

Bauman, Z. 2001. Community: Seeking Safety in an Insecure World. Cambridge: Polity Press; Oxford: Blackwell.

Bobbio, N. 2004. The Age of Rights. 8th ed. Translated by Carlos Nelson Coutinho. Rio de Janeiro: Campus.

Bonavides, P. 2000. Constitucional Law Course. 10th ed. Sao Paulo: Malheiros.

Chuwa, L. T. 2014. African Indigenous Ethics in Global Bioethics: Interpreting Ubuntu. New York: Springer.

Donders, Y. 2005. "Towards a Right to Cultural Identity in International Law Concerning Human Rights.” Pp. 123-142 in Cultural Diversity and Urban Development. São Paulo: Iluminuras.

Fraser, N. 2007. "Recognition Without Ethic?" Lua Nova, São Paulo 70:101-138.

FWD: The Historic Speech of George Derek-Vice-Ambassador of Israel in Norway (Arabic-Christian). 2014. Retrieved (http://www.youtube. com/ watch? v=8m6ux-IeNo4).

Geertz, C. 2011. "The World in Pieces: Culture and Politics at the End of the Century." Pp. 191-228 in New Light on Anthropology. 3rd ed. Rio de Janeiro: Jorge Zahar.
Hall, S. 2011. Cultural Identity in Postmodernity. Rio de Janeiro: DP\&A.

Honneth, A. 1995. The Struggle for Recognition: The Moral Grammar of Social Conflicts. Translated by J. Anderson. Cambridge: Polity Press.

Kimmerle, H. 2006. Ubuntu and Communalism in African Philosophy and Art. Retrieved (http://rozenbergquarterly. com/ubuntu-and-communalism-in-african-philosophy-andart).

Kunene, M. 1996. "The Essence of Being Human: An African Perspective." Inaugural Lecture. August 16, Durban.

Lafer, C. 1999. "Resistance and Effectiveness on the Defence of Human Rights in the International Plan on the Limits of the XXI Century." In The Fiftieth Anniversary of the Universal Declaration of Human Rights, edited by A. D. Amaral Junior and C. Perrone-Moisés. São Paulo: Editora da Universidade de São Paulo.

. 2005. The Internalization of Human Rigths: Constitution, Racism and International Relations. São Paulo: Manole.

Lévinas, E. 1993. Humanism of the Other Man. Translated by P. S. Pivatto. Petrópolis: Vozes.

—. 1997. Among Us: Essays on Alterity. Translated by P. S. Pivatto. Petrópolis: Vozes.

Manda, D. S. 2009. Ubuntu Philosophy as an African Philosophy for Peace. Retrieved (http://www.africafiles. org/article.asp?ID=20361).

Mandela, N. 2013. Notes to the Future: Words of Wisdom. Translated by N. Bandeira. Rio de Janeiro: Rocco.

Mokgoro, J. Y. 1997. "Ubuntu and the Law in South Africa." Presented at the First Colloquy "Constitution and Law". October 31, Potchefstroom.

Nussbaum, B. 2003. "Ubuntu: Reflection of a South African on Our Common Humanity." Reflections The SoL Journal 4(4):21-26.

Panikkar, R. 2002. Peace and Interculturalism: A Philosophical Reflection. Retrieved (http://www. raimon-panikkar.org/spagnolo/opere.html).

Peace Talks. 2014. Prose and Verse. Rio de Janeiro.

Ramose, M. B. 2003a. "The Ethics of Ubuntu." Pp. 324-330 in The African Philosophy Reader, 2nd ed., edited by P. H. Coetee and A. P. J. Roux. London: Routledge.

- 2003b. "The Philosophy of Ubuntu and Ubuntu as a Philosophy." Pp. 230-238 in The African Philosophy Reader, 2nd ed., edited by P. H. Coetee and A. P. J. Roux. London: Routledge.

Shutte, A. 2001. Ubuntu: An Ethic for a New South Africa. Pietermaritzburg: Cluster Publications.

Swanson, D. 2013. Doing Democracy. Retrieved (http://doingdemocracy.ning.com/profile/DaleneSwanson).

Walzer, M. 1999. On Toleration. Translated by A. Piseta. São Paulo: Martins Fontes. 


\section{Bios}

Flora Strozenberg, Ph.D., researcher, full professor, Department of Foundations in Legal, Political and Administrative Sciences, the Federal University of the State of Rio de Janeiro, Brazil; research fields: health law and bioethics.

Willis Santiago Guerra Filho, Ph.D., full professor, Department of Foundations in Legal, Political and Administrative Sciences, the Federal University of the State of Rio de Janeiro, Brazil; research fields: philosophy of law and ethics.

Luiz Otávio Ferreira Barreto Leite, MA, associate professor, Department of Foundations in Legal, Political and Administrative Sciences, the Federal University of the State of Rio de Janeiro, Brazil; research fields: ethics, history of literature, and anthropology.

Edna Raquel Santos Hogemann, Ph.D., associate professor, Department of Foundations in Legal, Political and
Administrative Sciences, the Federal University of the State of Rio de Janeiro, Brazil; research fields: ethics and bioethics.

Milanna Nagib, student of political science, Political Science College, the Federal University of the State of Rio de Janeiro, Brazil; research field: political anthropology.

Hellen Cristina Silva de Oliveira, student of political science, Political Science College, the Federal University of the State of Rio de Janeiro, Brazil; research field: political science.

Matheus Novais da Silva, student of law and political science, School of Law, Integrated Faculties Helio Alonso-FACHA, the Federal University of the State of Rio de Janeiro, Brazil; research fields: human rights and bioethics.

Ana Carolina Antão, MA candidate in Oswaldo Cruz Foundation-FIOCRUZ; Law College, the Federal University of the State of Rio de Janeiro, Brazil; research field: social history. 